in 15 years time. At the same time, society is attempting to promote independent living by the aged in example by improving inhome services and safety devices. In practice, this means that the number of people with a somewhat reduced functional ability living independently at home will increase notably over the years to come. This will be challenging in terms of fire safety. New types of preventive measures are required in order to improve the fire safety and reduce the fire deaths of elderly people living at home.

The Tampere Region is rising to the challenge by improving cooperation between the authorities by means of training, joint home visits, and jointly developed assessment criteria for the functional ability of the elderly. In addition to the authorities, training is also provided to pension organisations and groups, family caregivers and residents of senior buildings.

Finnish legislation dictates that perceived fire hazards must be reported to the rescue authorities. Reporting has been made as easy as possible and the process efficient. On the basis of the reports, rescue authorities have made visits to assess the fire safety risks and to propose improvements to the home owner and authority in charge.

Description of the problem As for elderly people, the main reason for fire deaths is their reduced functional ability. A lack of or weakened functional ability often increases fire risks and, on the other hand, reduces the ability to escape or even prevents escaping. The rescue department is preparing assessment criteria, together with the home help service of the City of Tampere, based on the areas of functional ability, which play a role in the fire safety of a resident. The criteria are used to assess a person's functional ability from three viewpoints: mobility, comprehension and perceptual ability. The person's need for fire safety related support measures is determined on the basis of the assessment.

Results Training, home visits and the assessment of the functional ability are used to improve the fire safety of homes and to prevent fires. It is equally important to come up with operations models and technical solutions for situations in which a fire breaks out despite preventive measures. The Tampere Region Rescue Department has developed an automatic, portable fireextinguishing system for private homes, in cooperation with a private company. The fire-extinguishing system is used to prevent a fire from escalating and becoming dangerous. This will minimise personal injuries and material damage.

Conclusions The above actions and matters constitute a whole, the ongoing assessment and development of which is necessary in order to improve the fire safety of elderly people and to reduce fire deaths.

\section{COOPERATION BETWEEN THE AUTHORITIES BRINGS SAFETY, SECURITY AND OPERATING MODELS TO DAILY LIFE}

${ }^{1}$ Janne Leinonen, ${ }^{2}$ Nina Juurakko-Vesikko, ${ }^{1}$ Veijo Kaján. ${ }^{1}$ Tampere Regional Rescue Department, Finland; ${ }^{2}$ Central Finland Police Department, Tampere Head Police Station, Finland

\subsection{6/injuryprev-2016-042156.51}

Background Along with the changing operating environment, the citizens' need to feel safe and secure has increased. This has increased the need for cooperation between the authorities in risk assessments and in practical safety and security work. Consequently, over recent years, the authorities and the organisations in the field have actively developed their forms of cooperation.
Objective The objective of the cooperation between the authorities is to increase the safety and security knowledge amongst the population, as well as affect people's attitudes.

Results The authorities use various channels of communication in their operations in a versatile way.

The conventional training events and drills for pupils and other population groups, as well as Facebook, Instagram, and Twitter provide an opportunity to convey information in the way that best suits the person concerned. In addition, the authorities support the forming of the safety and security culture of both public and private organisations by steering, instructing, and giving statements.

The forming of the safety and security culture is also produced by carrying out active cooperation between the authorities, which is concretised by various campaigns and training events.

Conclusion The cooperation between the authorities and a shared communication strategy are the best ways to support the maintained and increased feeling of safety and security amongst the citizens, their skills to identify safety and security risks in their environments, and their ability to recognise their own responsibilities.

\section{SAFETY AND HEALTH SECURITY OF ASYLUM SEEKERS IN EMERGENCY HOUSING, CASE FINLAND AND TAMPERE}

${ }^{1}$ Marja Nyrhinen, ${ }^{1}$ Sirpa Räsänen, ${ }^{2}$ Nina Juurakko-Vesikko, ${ }^{3}$ Valtteri Väyrynen. ${ }^{1}$ City of Tampere, Finland; ${ }^{2}$ Central Finland Police Department, Tampere Head Police Station, Finland; ${ }^{3}$ Tampere Regional Rescue Department, Finland

\subsection{6/injuryprev-2016-042156.52}

Background The police, Tampere Regional Rescue Department, the authorities of the City of Tampere, and the third sector have worked closely together in issues related to the asylum situation, particularly as far as safety and security are concerned. On the basis of propositions made by the City and the third sector, the Rescue Department has assessed the suitability of the proposed premises as emergency accommodation facilities from the viewpoint of fire safety. The police and the Rescue Department have visited the emergency accommodation facilities, together and separately, to ensure their safety. The Rescue Department has also visited emergency accommodation facilities and reception centres to speak to the immigrants about Finnish safety usage and the operation of rescue services and emergency medical care. In addition, the personnel were educated about fire safety issues. To support the integration of asylum-seekers, Tampere Regional Rescue Department will provide safety training as part of a more extensive integration plan.

The Finnish Immigration Service received $>32000$ asylum applications in 2015. In previous years the total has been between 2000 to 4000 . The number of asylum seekers coming to Finland via new routes (from Sweden around the Gulf of Bothnia, by ferries from Germany and by bike from Russia) increased rapidly in September. Most came without registration in other countries.

The sudden inflow of migrants urged emergency solutions in Finland. A registration centre opened in Tornio. Registration within 24 hours of those who enter Finland at Tornio helped, but lack of housing spaces caused problems to both the government and municipal officials.

Description of the problem Tampere and its surroundings are now housing about 1000 asylum seekers in emergency housing units (EHU) governed by Tampere municipality, The Finnish Red 